\title{
Clinical Characteristics and Course of Patients Entering Cardiac Rehabilitation with Chronic Kidney Disease: Data from the Italian Survey on Cardiac Rehabilitation
}

\author{
Francesco Giallauria, ${ }^{1}$ Francesco Fattirolli, ${ }^{2}$ Roberto Tramarin, ${ }^{3}$ Marco Ambrosetti, \\ Raffaele Griffo, ${ }^{5}$ Carmine Riccio, ${ }^{6}$ and Carlo Vigorito ${ }^{1}$ \\ ${ }^{1}$ Department of Translational Medical Sciences, Cardiac Rehabilitation Unit, University of Naples "Federico II," Via S. Pansini 5, \\ 80131 Naples, Italy \\ ${ }^{2}$ Department of Critical Care Medicine and Surgery, Cardiac Rehabilitation Unit, University of Florence and \\ Azienda Ospedaliero-Universitaria Careggi, Via delle Oblate 4, 50141 Florence, Italy \\ ${ }^{3}$ Division of Cardiac Rehabilitation, Fondazione Europea di Ricerca Biomedica, Via Uboldo 56, 20063 Cernusco S/N, Italy \\ ${ }^{4}$ Clinica "Le Terrazze," Via Foscolo 6/B, 21035 Cunardo, Italy \\ ${ }^{5}$ Cardiac Rehabilitation Unit, Department of Cardiology, La Colletta Hospital, Via del Giappone, 16011 Arenzano, Italy \\ ${ }^{6}$ Azienda Ospedaliera S. Anna e S. Sebastiano di Caserta, Via Gennaro Tescione 1, 81100 Caserta, Italy \\ Correspondence should be addressed to Francesco Giallauria; giallauria@libero.it
}

Received 13 May 2013; Accepted 9 June 2013

Academic Editors: Y. Hu, Y. Laufer, and M. Probst

Copyright (C) 2013 Francesco Giallauria et al. This is an open access article distributed under the Creative Commons Attribution License, which permits unrestricted use, distribution, and reproduction in any medium, provided the original work is properly cited.

This survey shows the clinical risk profile, resource utilization, pharmacologic treatment, and course of cardiac rehabilitation (CR) programs in patients with chronic kidney disease (CKD). Data from 165 CR units in Italy were collected online from January 28 to February 10, 2008. The study cohort consisted of 2281 patients: 200 CKD patients and 2081 non-CKD patients. CKD patients were older and showed more comorbidity and complications during CR, a more complex clinical course and interventions with less functional evaluation, and a different pattern of drug therapy at hospital discharge. CKD patients had higher mortality during CR programs due to heart failure, respiratory insufficiency, and cognitive impairment. These findings suggest that patients with CKD should not be denied access to CR, provided careful attention to clinical status, possible complications, optimization of drug therapy, and close followup.

\section{Introduction}

Chronic kidney disease (CKD) is a major public health problem, strongly associated with a high cardiovascular mortality [1]. The high prevalence of established traditional risk factors for atherosclerosis such as diabetes, hypertension, and older age and nontraditional risk factors such as high level of homocysteine, lipoprotein (a), fibrinogen, and C-reactive protein in patients with $\mathrm{CKD}$ contributes to an accelerated rate of coronary heart disease (CHD) [2].

The American Heart Association scientific statement on kidney disease and cardiovascular disease has recommended that patients with CKD be placed in the highest-risk group for prevention, detection, and treatment of CHD risk factors [3]. CKD is prevalent in patients with $\mathrm{CHD}$ and is associated with a poor prognosis [4].

Exercise training alone or as core component of cardiac rehabilitation (CR) programs has several beneficial effects reducing long-term morbidity and mortality [5], preventing cardiac remodelling $[6,7]$, and improving cardiovascular functional capacity, cardiac symptoms, and quality of life [8]. The improvement of endothelial function [9], the antiinflammatory properties [10], the improvement of neurohormonal and autonomic balance [11-14], and the reduction of oxidative stress [15] might be some of the putative mechanisms by which exercise training exerts its beneficial effects. 
TABLE 1: Demographics characteristics of the study population $(n, \%)$.

\begin{tabular}{lccc}
\hline & CKD $(n=200)$ & Non-CKD $(n=2081)$ & $P$ value \\
\hline Age (years) (mean \pm SD) & $73.6 \pm 9.9$ & $66.3 \pm 11.7$ & $1536(73.8)$ \\
Gender (male) & $141(70.5)$ & & \\
Cardiovascular risk factors ${ }^{1}$ & & $854(41.0)$ & 0.31 \\
$0-2$ (low) & $57(28.5)$ & $1046(50.3)$ & 0.0003 \\
3-5 (medium) & $113(56.5)$ & $181(8.7)$ & \\
$>5$ (high) & $30(15.0)$ & & \\
\hline
\end{tabular}

${ }^{1}$ Smoking, family history of early coronary heart disease, high blood pressure, hypercholesterolemia, body mass index $>27$, diabetes, sedentary lifestyle, and early menopause.

Of note, some of the 1 beneficial effects of exercise-based CR observed in the general population of CHD patients have also been reported in CKD patients [16, 17]. To our knowledge, there are no data that specifically describe in large population of patients the prevalence of CKD in patients with $\mathrm{CHD}$ undergoing CR programs, their clinical characteristics, and course during the CR program.

The present survey aimed at providing an insight in the clinical characteristics and course of a CKD population in the real world of CR in Italy.

\section{Methods}

2.1. Study Design. The multicenter, prospective observational study design of the ISYDE-2008 has been described in detail elsewhere $[18,19]$. In summary, the primary purpose of this study was to take a snapshot on current organization, settings, and provision of CR in Italy and to describe the patient population referred to $\mathrm{CR}$, giving a comprehensive and detailed description of clinical characteristics, risk profile, diagnostic procedures, exercise and educational program, discharge modalities, treatment at discharge, and follow-up schedules. The enrolment period lasted from January 28 to February 102008. Data were collected on a web-based case report form, which reported data on clinical characteristics, diagnostic procedures, exercise and educational programs, treatment, and follow-up plans of all the consecutive patients discharged from CR programs in the 2 -week study period. The present study focused on CKD patients. As suggested by the National Kidney Foundation Kidney Disease Outcome Quality Initiative, CKD was prospectively defined and considered present if the estimated glomerular filtration rate (eGFR) was $<60 \mathrm{~mL} /$ $\mathrm{min} / 1.73 \mathrm{~m}^{2}$ for 3 months at study entry [20]. The eGFR was calculated using the abbreviated Modification of Diet in Renal Disease Study Equation [21]: eGFR (mL/min/1.73 m² of body surface area $)=186 \times($ serum creatinine in $\mathrm{mg} / \mathrm{dL})-$ $1.154 \times$ (age in years) $-0.203 \times 0.742$ in female subjects. As a part of geriatric multidimensional evaluation, performed in about one-fourth of our population, cognitive function was evaluated by MMSE [22], and cognitive impairment was assigned when corrected MMSE value was $<21$.

2.2. Participating Centers. The survey was designed to be carried out in all Italian residential and outpatient CR centers. Centers were invited to participate in the survey on a purely voluntary basis by the executive board of the study and by the regional GICR-IACPR coordinator, who was responsible for interfacing with the investigators in each of the participating centers and overlooked the implementation of the survey protocol. Data collected in the study refer to $165 \mathrm{CR}$ units ( $87 \%$ of all invited facilities). These CR units, representative of national CR organization, were subdivided in 103 (62.4\%) residential units, 18 (10.9\%) facilities with day-hospital care, and 33 (20\%) facilities with outpatient CR (information not available in $11 \mathrm{CR}$ units $(6.7 \%)$ ). The complete list of ISYDE2008 investigators and participating centers with names of the directors or contact physicians is reported in the Acknowledgments.

2.3. Role of the Funding Source. No funding sources had any role in the study design, conduct, data collection, analysis, data interpretation, or writing of this paper. The GICRIACPR coordinated the study, managed the data, and undertook all analyses. All members of the scientific board and writing committees had full access to the database and assumed final responsibility for the results submitted for publication.

2.4. Statistical Analysis. The main analysis was performed subdividing the study cohort into two groups, according to the diagnosis of CKD. Data are expressed as means \pm standard deviation (SD) or proportions. Comparisons between groups were performed by unpaired $t$-test, $\chi^{2}$ or Fisher exact test as required. Correlations between variables were assessed with Pearson's correlation coefficient. Predictors of death were evaluated with multivariate logistic regression analysis. All analyses were performed using SAS (version 9.1, Cary, NC) with significance set at $P<0.05$.

\section{Results}

Table 1 summarizes the demographic characteristics of the study population. The study cohort consisted of 2281 patients (66.9 \pm 11.8 yrs): 200 (71.3 \pm 12.2 yrs, $66 \%$ male $)$ CKD patients and 2081 (66.3 \pm 11.6 yrs, $74 \%$ male) non-CKD patients. CKD patients showed a significantly higher cardiovascular risk factors score (including smoking, history, hypertension, dyslipidemia, obesity, diabetes, sedentary lifestyle, and early menopause) compared to the non-CKD cohort $(P=0.0003)$. 
TABLE 2: Previous interventions and comorbidities $(n, \%)$.

\begin{tabular}{|c|c|c|c|}
\hline & $\mathrm{CKD}(n=200)$ & Non-CKD $(n=2081)$ & $P$ value \\
\hline Previous myocardial infarction & $77(38.5)$ & $426(20.5)$ & $<0.0001$ \\
\hline Previous percutaneous transluminal coronary angioplasty & $37(18.5)$ & $188(9.0)$ & $<0.0001$ \\
\hline Previous cardiac surgery & $33(16.5)$ & $217(10.4)$ & 0.008 \\
\hline Heart failure & $69(24.2)$ & $131(6.6)$ & $<0.0001$ \\
\hline Carotid arteries atherosclerosis ${ }^{1}$ & $20(10.0)$ & $140(6.7)$ & 0.08 \\
\hline Peripheral artery disease ${ }^{2}$ & $25(12.5)$ & $126(6.0)$ & 0.0005 \\
\hline Chronic obstructive pulmonary disease & $52(26.0)$ & $246(11.8)$ & $<0.0001$ \\
\hline Respiratory insufficiency & $19(9.5)$ & $93(4.5)$ & 0.002 \\
\hline Hepatic disease & $11(5.5)$ & $52(2.5)$ & 0.01 \\
\hline Stroke & $12(6.0)$ & $71(3.4)$ & 0.06 \\
\hline Cognitive impairment & $21(10.5)$ & $43(2.1)$ & $<0.0001$ \\
\hline Diabetes & $97(48.5)$ & $378(18.2)$ & $<0.0001$ \\
\hline Orthopedic/joints/immune-related disease & $29(14.5)$ & $178(8.5)$ & 0.005 \\
\hline
\end{tabular}

${ }^{1}$ Stenosis $>70 \%$ or previous revascularization; ${ }^{2}$ Fontaine stage $>1$ or previous revascularization.

TABLE 3: Complications during cardiac rehabilitation programs $(n, \%)$.

\begin{tabular}{|c|c|c|c|}
\hline & $\mathrm{CKD}(n=200)$ & Non-CKD $(n=2081)$ & $P$ value \\
\hline Atrial fibrillation & $49(24.5)$ & $403(19.4)$ & 0.08 \\
\hline Severe ventricular arrhythmias ${ }^{1}$ & $11(5.5)$ & $79(3.8)$ & 0.23 \\
\hline Permanent pacemaker implantation & $13(6.5)$ & $57(2.7)$ & 0.003 \\
\hline Acute myocardial infarction & $4(2.0)$ & $31(1.5)$ & 0.57 \\
\hline Cerebrovascular events $^{2}$ & $5(2.5)$ & $36(1.7)$ & 0.43 \\
\hline Cognitive impairment ${ }^{*}$ & $7(2.5)$ & $31(1.5)$ & 0.03 \\
\hline Anemia $^{3}$ & $38(19.0)$ & $275(13.2)$ & 0.02 \\
\hline Worsening of CKD or new onset of renal failure ${ }^{4}$ & $63(31.5)$ & $56(2.7)$ & $<0.0001$ \\
\hline Hepatic insufficiency & $4(2.0)$ & $14(0.7)$ & 0.04 \\
\hline Sternal revision & $7(3.5)$ & $27(1.3)$ & 0.01 \\
\hline Massive pleural effusion needing thoracenthesis & $6(3.0)$ & $51(2.5)$ & 0.63 \\
\hline Inotropic support/mechanical assistance & $24(12.0)$ & $88(4.2)$ & $<0.0001$ \\
\hline Respiratory assistance $^{5}$ & $17(8.5)$ & $78(3.7)$ & 0.0001 \\
\hline Systemic infections & $16(8.0)$ & $62(3.0)$ & 0.0002 \\
\hline Death & $4(2)$ & $11(0.5)$ & 0.02 \\
\hline
\end{tabular}

${ }^{1}>30 \mathrm{sec}$ or symptomatic ventricular tachycardia; ${ }^{2}$ stroke, transient ischemic attack; ${ }^{3} \mathrm{Hb} \leq 10 \mathrm{~g} / \mathrm{dL}$ or $\geq 3 \mathrm{~g} / \mathrm{dL}$ reduction with respect to the preindex event value; ${ }^{4}$ creatinine increase $\geq 1 \mathrm{mg} / \mathrm{dL} ;{ }^{5}$ including oxygen therapy, mechanical ventilation, continuous positive airway pressure (cPAP), bilevel positive airway pressure (biPAP) $>96 \mathrm{~h} .{ }^{*}$ Worsening of cognitive impairment or new onset of cognitive impairment.

Compared to non-CKD, CKD patients showed a greater frequency of previous interventions and comorbidities such as myocardial infarction, percutaneous coronary intervention (PCI), cardiac surgery, heart failure, diabetes, peripheral artery disease (PAD), chronic obstructive pulmonary disease (COPD), cognitive impairment, and orthopedic/immunological diseases (Table 2).

During CR programs, CKD patients underwent more permanent pacemaker implantation or developed more complications such as anemia, systemic infections, and worsening of CKD and required more frequently inotropic support or respiratory assistance compared to non-CKD patients (Table 3).

Differences between CKD and non-CKD patients were also detected in diagnostic or therapeutic procedures during
CR (Table 4). Compared to non-CKD, CKD patients less likely underwent diagnostic procedures such as exercise stress testing on admission or at discharge, whereas no significant differences were found among groups in six-minute walking test (6MWT) on admission or at discharge and cardiopulmonary exercise stress tests at discharge (Table 4). As many as 77 CKD patients (38\%) received no physical performance test (nor 6MWT, exercise stress testing, or cardiopulmonary exercise testing); this proportion was significantly greater than that in non-CKD patients $(20 \%, P<0.0001)$. Compared to non-CKD not performing any physical performance testing, CKD patients not performing any physical performance testing showed a higher percentage of comorbidities such as myocardial infarction (36\% versus $16 \%, P<0.0001$ ), percutaneous coronary intervention (PCI) (16\% versus $5 \%$, 
TABLE 4: Diagnostic and therapeutic procedures during cardiac rehabilitation programs $(n, \%)$.

\begin{tabular}{|c|c|c|c|}
\hline & $\mathrm{CKD}(n=200)$ & Non-CKD $(n=2081)$ & $P$ value \\
\hline 6-minute walking test on admission & $79(39.5)$ & $904(43.4)$ & 0.28 \\
\hline 6-minute walking test at discharge & $83(41.5)$ & $864(41.5)$ & 0.99 \\
\hline Exercise stress testing on admission & $9(4.5)$ & $437(21.0)$ & $<0.0001$ \\
\hline Exercise stress testing at discharge & $27(13.5)$ & $678(32.6)$ & $<0.0001$ \\
\hline Cardiopulmonary exercise stress testing on admission & $4(2.0)$ & $118(5.7)$ & 0.02 \\
\hline Cardiopulmonary exercise stress testing at discharge & $16(8.0)$ & $141(6.8)$ & 0.51 \\
\hline Holter electrocardiogram & $88(44.0)$ & $832(40.0)$ & 0.27 \\
\hline Venous infusions & $68(23.9)$ & $171(8.6)$ & $<0.0001$ \\
\hline Thoracentesis & $6(3.0)$ & $26(1.2)$ & 0.04 \\
\hline Blood transfusions & $9(4.5)$ & $13(0.6)$ & $<0.0001$ \\
\hline Geriatric multidimensional evaluation & $58(29.0)$ & $396(19.0)$ & 0.0007 \\
\hline Computed tomography & $16(8.0)$ & $73(3.5)$ & 0.002 \\
\hline Ultrasounds & $44(22.0)$ & $330(15.6)$ & 0.02 \\
\hline Individual exercise sessions & $92(46.0)$ & $495(23.8)$ & $<0.0001$ \\
\hline
\end{tabular}

TABLE 5: Drug therapy at hospital discharge after cardiac rehabilitation programs.

\begin{tabular}{|c|c|c|c|}
\hline & $\mathrm{CKD}(n=200)$ & Non-CKD $(n=2081)$ & $P$ value \\
\hline Inhibitors of angiotensin-converting enzyme & $86(43.0)$ & $1171(56.3)$ & 0.0003 \\
\hline Angiotensin II receptor blockers & $46(23.0)$ & $341(16.4)$ & 0.02 \\
\hline Beta-blockers & $133(66.5)$ & $1433(68.9)$ & 0.49 \\
\hline Nitrates & $68(34.0)$ & $372(17.9)$ & $<0.0001$ \\
\hline Diuretics & $156(78.0)$ & $1012(48.6)$ & $<0.0001$ \\
\hline Statins & $119(59.5)$ & $1391(66.8)$ & 0.03 \\
\hline Omega-3 fatty acids & $26(13.0)$ & $352(16.9)$ & 0.15 \\
\hline Oral anticoagulant therapy & $72(36.0)$ & $532(25.6)$ & 0.001 \\
\hline Aspirin & $100(50.0)$ & $1408(67.7)$ & $<0.0001$ \\
\hline Digitalis & $23(11.5)$ & $101(4.8)$ & $<0.0001$ \\
\hline Amiodarone & $25(12.5)$ & $107(5.1)$ & $<0.0001$ \\
\hline Calcium channel blockers & $51(25.5)$ & $385(18.5)$ & 0.01 \\
\hline Antidepressant & $21(10.5)$ & $120(5.8)$ & 0.008 \\
\hline
\end{tabular}

$P=0.0008)$, carotid arteries atherosclerosis $(13 \%$ versus $6 \%$, $P=0.02)$, peripheral artery disease (PAD) $(14 \%$ versus $6 \%$, $P=0.006)$, heart failure (32\% versus $12 \%, P<0.0001)$, chronic obstructive pulmonary disease (COPD) (31\% versus $13 \%, P<0.0001)$, diabetes (54\% versus $16 \%, P<0.0001$ ), hepatic disease ( $6 \%$ versus $2 \%, P=0.02)$, cognitive impairment (16\% versus 5\%, $P=0.0005)$, and orthopedic disease (26\% versus $14 \%, P=0.007$ ) and a higher percentage of complications during the CR program such as anemia $(21 \%$ versus $9 \%, P=0.003)$, worsening of $\mathrm{CKD}(30 \%$ versus $3 \%, P<0.0001$ ), need of inotropic support (5\% versus $1 \%$, $P=0.007)$ or respiratory assistance (8\% versus $3 \%, P=$ $0.02)$, infections ( $12 \%$ versus $4 \%, P=0.007)$, and blood transfusions ( $8 \%$ versus $2 \%, P=0.005$ ), respectively.

Echocardiography showed a lower percentage of CKD patients with preserved left ventricular ejection fraction (LVEF > 50\%) compared to non-CKD patients (37\% versus $61 \%, P<0.0001$, resp.) and a higher percentage of moderate (LVEF $=30-49 \%, 37 \%$ versus $26 \%, P<0.0001$, resp.) and severe (LVEF $<30 \%, 17 \%$ versus 5\%, $P<0.0001$, resp.) compromise of LVEF compared to the non-CKD cohort.

Patients with CKD also underwent more frequent geriatric multidimensional evaluation, and CT or ultrasound diagnosis, venous infusion, blood transfusion, or thoracentesis. They also performed preferentially more individually tailored rather than group exercise training session.

At discharge, compared to non-CKD, CKD patients were less frequently prescribed angiotensin-converting enzyme inhibitors, statins, and aspirin. Conversely, CKD patients were more frequently prescribed angiotensin II receptor blockers, nitrates, diuretics, oral anticoagulant therapy, digitalis, amiodarone, insulin, oral hypoglycemic drugs, and calcium channel blockers (Table 5). No significant differences were observed in beta-blockers or omega- 3 fatty acids discharge prescription among the 2 groups (Table 5 ).

CKD patients were less likely discharged home (88\% versus $91 \%, P=0.05)$ and more likely transferred to intensive care units ( $8 \%$ versus $4 \%, P=0.005)$. CKD patients 
had higher death rate during CR programs $(2.0 \%$ versus $0.5 \%, P=0.02$ ). After adjusting for age, ejection fraction, comorbidities (acute myocardial infarction, percutaneous coronary intervention, cardiac surgery, carotid artery critical lesions, peripheral artery disease, respiratory insufficiency, heart failure, diabetes, stroke, and cognitive impairment), and complications during CR program (atrial fibrillation and severe ventricular arrhythmias), multivariate logistic analysis showed that heart failure (OR 1.6, 95\% CI, 1.1 to $2.4, P=$ 0.04), respiratory insufficiency (OR 2.4, 95\% CI, 1.4 to 4.0, $P=0.0007$ ), and cognitive impairment (OR 4.5, 95\% CI, 2.5 to $8.1, P<0.0001)$ were significant predictors of death in CKD patients.

\section{Discussion}

To the best of our knowledge, the present study is the first to explore the characteristics of the "real world" CKD patients admitted to CR programs in Italy. The principal findings of this study were the higher burden of cardiovascular risk factors and comorbidities associated with a worse clinical course during CR in patients with CKD compared to patients without CKD.

This survey revealed that only about $9 \%$ of patients admitted to CR had diagnosed CKD, a number significantly lower than that reported in a cohort of patients with postmyocardial infarction followed at the Mayo Clinic (29.6\%), among patients enrolled in the Valiant Trial (33.6\%), among a national cohort of elderly patients with myocardial infarction (37\%), and in a other cohorts of patients referred for CR (25.6\%) [4, 23-25]. The lower percentage of CKD patients found in our study, compared to previous reports in CR environment [25], may reflect indication bias, with a the tendency of deny referral to CR programs of patients with $\mathrm{CKD}$ in Italy. In addition, in agreement with previously reported studies, our patients with CKD had a greater burden of comorbidities and cardiovascular risk factors than their non-CKD counterparts.

This survey showed the higher prevalence of CKD patients participating to CR programs with previous PCI or coronary artery bypass graft (CABG). Patients with $\mathrm{CKD}$ undergoing myocardial revascularization have worse survival than other CAD patients [26, 27]. Several studies have reported that PCI in patients with CKD may be associated with poor long-term results $[28,29]$. In a large retrospective analysis of patients undergoing elective PCI with balloon angioplasty or/and bare-metal stent implantation, CKD was found to have a negative prognostic impact, similar to that of diabetes, on cardiovascular morbidity and mortality [30]. Recently, Ashrith et al. [31] showed that in patients with CKD and multivessel CAD, CABG led to better survival than PCI with drug-eluting stents, but CABG patients had a greater short-term risk of requiring permanent hemodialysis. In our study, despite the worsening of CKD observed in many patients, no patient required hemodialysis. This might be a consequence of a selection bias, since our observational study likely represents a selected population of patients with CKD after an acute cardiac event, where the worst patients requiring hemodialysis immediately after coronary revascularization were not addressed to CR. Future prospective studies are needed in order to evaluate the effect of CR in CKD patients undergoing PCI or CABG in terms of postprocedure hemodialysis dependence and mortality.

Compared to non-CKD patients, we found a roughly doubled prevalence of symptomatic PAD in CKD patients enrolled to CR programs (12.5\% versus $6 \%, P=0.0005)$. Selvin and Erlinger [32] reported that low kidney function (OR 2.00, 95\% CI 1.08 to 3.70) was positively associated with prevalent PAD. In patients with $\mathrm{CAD}$, the prevalence of previously unrecognized $\mathrm{PAD}$ is $15 \%$ [33]. In this survey, $7 \%$ of CKD patients had coexisting diabetes and PAD, thus representing a very high-risk patient population referred to CR programs.

This survey also highlighted the higher prevalence of diabetes in $\mathrm{CKD}$ patients participating to $\mathrm{CR}$ programs compared to the non-CKD cohort (48\% versus $18 \%, P<$ 0.0001 , resp.). This high prevalence of diabetes in our CKD patients is not surprising, since diabetes is one of the major risk factor for CKD and for CHD [34].

Despite the fact that geriatric multidimensional evaluation was performed in less than one-third of the patients, the present survey showed that cognitive impairment prevalence (10 versus $2 \%$ ) and worsening of cognitive impairment during CR (2.5 versus $1.5 \%)$ were significantly higher in CKD patients compared to the non-CKD cohort. In fact, CKD is known to independently affect cognitive status: recent studies have shown impaired kidney function to be associated with greater prevalence of cognitive impairment [35], a morerapid rate of cognitive decline [36], and incident cognitive impairment [37, 38].

A previous study showed that in patients with mild cognitive impairment of heterogeneous etiology including vascular, metabolic, or endocrine factors, CKD was an independent risk factor for cognitive impairment [39], and it showed that CKD in older adults with mild cognitive impairment was a potentially modifiable risk factor.

An additional cause of mental deterioration in our CKD patients was the frequent association with CHF. In our survey, $24.2 \%$ of CKD patients had CHF. It is well recognized that $\mathrm{CHF}$ is an independent factor affecting cognitive impairment [40], and cognitive dysfunction and heart failure are common conditions in the elderly [41]. Mild cognitive impairment, a subtle but measurable deficit usually involving the memory domain, is the most commonly reported dysfunction in elderly patients with heart failure, being detectable in more than half of the patients [40]. Potential underlying mechanisms for cognitive dysfunction in heart failure may involve low cardiac output status with consequent cerebral hypoperfusion as well as increased risk of cerebrovascular ischemic events [40]. Therefore, these findings suggest that an initial evaluation of cognitive performance should be implemented in CKD patients, especially in older patients and those with CHF.

The present survey showed higher prevalence of anemia in CKD patients compared to the non-CKD cohort $(19 \%$ versus $13 \%, P=0.02)$. It is well known that anemia is a very common feature of CKD patients [42], and it is not 
surprising that in patients with $\mathrm{CKD}$ undergoing $\mathrm{CABG}$ surgery or other invasive procedures anemia may be even more frequent. Reduced hemoglobin levels and CKD are common and interrelated factors in $\mathrm{CHF}[43,44]$.

Chronic kidney disease can contribute to the development and exacerbation of heart failure and progressive heart failure contributes to renal hypoperfusion and activation of inflammatory factors, which can lead to the development or worsening of kidney dysfunction. These findings suggest that in CKD patients during CR hemoglobin level should be closely monitored and raised to acceptable levels, especially in older and CHF patients [43]. It is also recommended that in CHF patients with CKD the hemoglobin values should not be raised beyond $12 \mathrm{mg} / \mathrm{dL}$, in order to avoid risk of thrombosis [45].

The present survey also highlighted that larger proportion of CKD patients did not perform any type of physical performance test compared to the non-CKD cohort. This might have prognostic relevance, since the lack of referral to exercise stress testing is by itself a negative prognostic indicator [46].

The present survey revealed also interesting differences relatively to drugs use. The rather low discharge indication to statin in the total populations is a consequence of the difficulties of adopting in the real clinical world the recommendations of international guidelines regarding secondary prevention [47] or of the presence of many patients after noncoronary surgery not requiring statins (59.5\% (CKD) versus $66.8 \%$ (non-CKD patients), $P=0.03$ ). Moreover, $\mathrm{CKD}$ patients showed a higher use of diuretics that might have precipitated in some patient in the worsening of CKD [48].

Finally, complications (particularly arrhythmias, pump failure requiring inotropic support, respiratory insufficiency, worsening of CKF, or infections) and mortality during CR were higher in CKD patients compared to the non-CKD cohort, reflecting the higher clinical risk profile of these patients after an acute cardiac event. In patients with $\mathrm{CHD}$ or CHF, CKD has been identified as an important predictor of adverse outcome and increased morbidity [4, 23, 24]. Anavekar et al. [4] reported a 10\% increase in the hazard of death and nonfatal cardiovascular outcomes after myocardial infarction for every 10 -unit decrease in GFR below $81 \mathrm{~mL} / \mathrm{min}$ per $1.73 \mathrm{~m}^{2}$. Wright et al. [23] reported a 3-fold increase in inhospital mortality after myocardial infarction in individuals with mild renal failure $\left(\mathrm{GFR}=51-75 \mathrm{~mL} / \mathrm{min}\right.$ per $\left.1.73 \mathrm{~m}^{2}\right)$, a 7-fold increase among those with moderate renal failure $\left(\mathrm{GFR}=35-50 \mathrm{~mL} / \mathrm{min}\right.$ per $\left.1.73 \mathrm{~m}^{2}\right)$, and a $>10$-fold increase among patients with severe renal failure. Bruch et al. [49] reported a 3-fold increase of cardiac events in $\mathrm{CHF}$ patients with CKD; and outcome was significantly worse in CKD patients than in patients without CKD (event-free survival rate $51 \%$ versus $87 \%$ in those without CKD, $P=0.001$ ). Therefore, more attention to the clinical stabilization of these patients is required during CR.

Our study has several limitations. The observational nature of the study cannot rule out that the more severely compromised patients with CKD were not addressed to CR and, therefore, those described in our study may represent a selected relatively healthy minority. The number of patients with CKD reported in the present survey is very small (about $9 \%$ of the overall population). This makes the study underpowered for a deepened interpretation. This probably depends on the very small time of the enrolment period (only two weeks). The combination of data from CR centers offering very different cardiac rehabilitation regimens (e.g., residential versus outpatients) is another confounder. The observational nature of the study cannot rule out that the more severely compromised patients with CKD were not addressed to CR and, therefore, those described in our study may represent a selected more relatively healthy minority. Moreover, according to recent evidence [50-52], the present survey did not collect data regarding modality of exercise training regimen (interval versus continuous) or the dose of exercise (in terms of volume and intensity) that can greatly affect the functional and clinical parameters (together with outcome) of CKD patients. Another major limitation of the present study was the lack of reporting some important functional and clinical parameters of possible interest; this was due to the short-term survey type of study, which collected the essential data in order to characterize the demographic and clinical course of the patients. Despite these limitations, the survey successfully highlighted crucial differences in the clinical characteristics, risk profile, management, and short term outcome in CKD patient population entering CR programs in Italy, compared to non-CKD patients.

In conclusion, this survey shows in a large population the clinical risk profile, resource utilization, pharmacologic treatment, and course of CR programs in CKD patients, compared to non CKD patients. In the future, prospective studies are needed in order to identify the best strategies for expanding referral to $\mathrm{CR}$ in more compromise patients, fostering the application of tailored functional evaluation, optimization of pharmacological and nonpharmacological treatment, and adherence to secondary prevention guidelines, with the aim of reducing in-hospital complications and improving functional recovery, long-term mortality, morbidity, and quality of life in CKD patients. Therefore, patients with CKD should not be denied access to $\mathrm{CR}$, provided careful attention to clinical status, possible complications, optimization of drug therapy, and close followup.

\section{Acknowledgments}

On behalf of the ISYDE-2008 Investigators of the Italian Association for Cardiovascular Prevention and Rehabilitation (GICR-IACPR). ISYDE-2008 Study Investigators. Scientific Board. R. Tramarin (Cernusco S/N-MI), R. Griffo (Arenzano, GE), C. Riccio (Caserta), R. Carlon (Cittadella, PD), A. Castello (Palermo), M. Ferratini (Milano), C. Schweiger (Milano), C. Chieffo (Napoli), C. Vigorito (Napoli). Writing Committee. R. Tramarin (Cernusco S/N-MI), C. Vigorito (Napoli); M. Ambrosetti (Cunardo, VA), S. De Feo (Peschiera del Garda, VR), R. Griffo (Arenzano, GE), M. Piepoli (Piacenza), C. Riccio (Caserta). Executive Committe. M. Ambrosetti (Cunardo, VA), S. De Feo (Peschiera del Garda, VR), T. Diaco (Rivolta d'Adda, CR). Delegati Regionali del 
Gruppo Italiano di Cardiologia Riabilitativa e Preventiva: Abruzzo: C. Ciglia (Chieti), Basilicata: A. Lapolla (Policoro, MT), Calabria: F. Pietropaolo (Soriano Calabro, VV), Campania: G. Furgi (Telese Terme, BN), Friuli Venezia Giulia: G. Martin (Sacile, PN), Emilia Romagna: P. Semprini (Rimini), Lazio: A. Avallone (Roma), Liguria: D. Bertoli (Sarzana, SP), Lombardia: T. Diaco (Rivolta d'Adda, CR), Marche: R. Belardinelli (Ancona), Piemonte: F. Soffiantino (Lanzo Torinese, TO), Puglia: D. Scrutinio (Cassano Murge, BA), Sardegna: P. Maxia (Cagliari), Sicilia: R. Coco (Catania), Toscana: C. Giustarini (Volterra, PI), Umbria: P. Anniboletti (Perugia), Veneto: G. Favretto (Motta di Livenza, TV). Technical Support. P. Vaghi (Saronno), P. Calisi (Arenzano, GE), C. Chiavetta (Genova), Aristea S.p.A. (Genova), Segno \& Forma S.p.A. (Milano). ISYDE-2008 Investigators (Italian Regions in Italic). Abruzzo: Leonello Guarracini, Presidio Ospsaledaliero Tagliacozzo, Tagliacozzo; Carlo Ciglia, Casa di Cura Villa Pini D’Abruzzo, Chieti; Giorgio, Marcellini, Presidio Ospedaliero S. Omero, S. Omero. Calabria: M. Iannopollo, Presidio Ospedaliero Siderno, USL 9 Locri (RC), Siderno; Gennarino Borrello, Azienda Ospedaliera Mater Domini, Catanzaro; Milena Matta, Presidio Ospedaliero di Cetraro, Cetraro; N. Peccerillo, Ospedale di Mormanno, ASL 2 Castrovillari, Mormanno; Franco Boncompagni, Ospedale dell'Annunziata, Cosenza; Achille Amici, Casa di Cura "San Francesco", Mendicino (CS), Mendicino; Francesco Pietropaolo, Presidio Ospedaliero, Soriano Calabro; Emidio Feraco, IRCCS INRCA, Cosenza; G. Pulitano, Presidio Ospedaliero Policlinico Madonna della Consolazione, Reggio Calabria; Ermete Tripodi, ASP 5 Regione Calabria, Scilla. Campania: Giuseppe Furgi, IRCCS Fondazione Salvatore Maugeri, Telese Terme; Carmelo Chieffo, Casa di Cura Clinical Center, Napoli; Soccorso Capomolla, Presidio Ospedaliero Polispecialistico Don Gnocchi Onlus, Sant'Angelo dei Lombardi; Paolo Golino, Azienda Ospedaliera di Caserta, Dipartimento di Cardiologia, Caserta; Gennaro Parrilli, Campolongo Hospital S.p.A. Casa di Cura, Eboli; Antonio Di Patria, Casa di Cura Villa delle Magnolie, Castel Morrone; Claudio Di Gioia, Casa di Cura Privata Villa Margherita, Istituto S. Giuseppe Moscati, Benevento; Domenico Micieli, Azienda Ospedaliera V. Monaldi, Napoli; Carlo Vigorito, Azienda Universitaria Policlinico, Università di Napoli Federico II, Napoli; Silvio Perrotta, ASL Napoli 1, Napoli; Alessandro Rubino, Azienda S. G. Moscati, Avellino; Vincenzo Aulitto, Centro Serapide S.p.A., Pozzuoli; Gerardo Riccio, Ospedale di Nocera, Nocera Inferiore. Emilia Romagna: Luciano Codec, Azienda Universitaria Ospedale S. Anna, Ferrara; Paolo Coruzzi, Fondazione Don Carlo Gnocchi, Onlus, Parma; Enrico Violi, Azienda Ospedaliera di Reggio Emilia, Castelnovo Monti; Massimo Nardini, Ospedale Regina Margherita, Castelfranco Emilia; Stefano Urbinati, Azienda USL di Bologna, Bologna; Sylvia Dcruz, Casa di Cura Privata ad Indirizzo Riabilitativo San Giacomo srl, Ponte dell'Olio; Pierluigi Semprini, Ospedale Infermi Rimini, Rimini; Massimo Piepoli, Azienda Unità Sanitaria Locale di Piacenza, Piacenza; Alessandro Fucili, Ospedale Sant’Anna, Ferrara; Massimo Cerulli, Ospedale Privato Accreditato Villa Pineta, Gaiato di Pavullo N/F; Bini Roberto, Azienda USL Cesena, Cesenatico; Guido Balestra, Villa Maria Cecilia Hospital, Cotignola. Friuli Venezia
Giulia: Dulio Tuniz, IMFR Udine, ASS N. 4, Udine; Giovanni Martin, Azienda Ospedaliera Santa Maria degli Angeli Pordenone, Sacile; Pierpaolo Gori, Casa di Cura Pineta del Carso, Aurisina; Roberto Marini, ASS N. 2 Isontina, Gorizia; Tullio Morgera, Ospedale San Polo, Monfalcone. Lazio: Franco Di Mario, Istituto Clinico Riabilitativo Villa delle Querce, Nemi; Maurizio Volterrani, IRCCS San Raffaele Pisana, Roma; Alfonso Galati, Presidio Ospedaliero Santo Spirito, Presidio Villa Betania, ASL Roma E, Roma; Alessandro Salustri, Policlinico Luigi Di Liegro, Roma; Anna Patrizia Jesi, Presidio Ospedaliero Salus Infirmorum, Roma; Augusto Lacch, Azienda Ospedaliera San Camillo, Forlanini, Roma; Francesco Loperfido, Complesso Integrato Columbus. Università Cattolica del Sacro Cuore, Roma. Liguria: Luca Corsiglia, Istituto Cardiovascolare Camogli, Ruta di Camogli; Raffaele Griffo, ASL 3 Genovese, Arenzano; Paolo Pantaleo, Struttura Ospedaliera Privata Accreditata Villa Azzurra, Rapallo; Guido Gigli, Regione Liguria ASL 4, Centro Regionale di Riabilitazione Cardiologica, Sestri Levante; Daniele Bertoli, ASL 5 Spezzino, Sarzana. Lombardia: Diego Marchesi, Clinica Domus Salutis Ancelle della Carità, Brescia; Oreste Febo, IRCCS Fondazione Salvatore Maugeri, Montescano; Franco Cobelli, IRCCS Fondazione Salvatore Maugeri Pavia, Pavia; Claudio Malinverni, Azienda Ospedaliera “Bolognini”, Seriate; Maurizio Ferratini, Fondazione Don Gnocchi Onlus, Milano; Norman Jones, Ospedale Trabattoni Ronzoni, Seregno; Claudio Anzà, Multimedica Holding, Presidio Ospedaliero di Castellanza, Castellanza; R. Frizzelli, Azienda Ospedaliera C. Poma di Mantova, Bozzolo; Paolo Gei, Spedali Civili di Brescia, Gardone Riviera; Flavio Acquistapace, Policlinico di Monza, Monza; Roberto Pedretti, IRCCS Fondazione Salvatore Maugeri, Tradate; Roberto Tramarin, Fondazione Europea di Ricerca Biomedica, Onlus, Cernusco S/N, Milano; Stefano Carugo, Centro di Cardiologia Riabilitativa, Pio Albergo Trivulzio, Milano; Gabriella Malfatto, Istituto Auxologico Italiano IRCCS, Milano; Tommaso Diaco, Azienda Ospedale Maggiore di Crema, Rivolta D’Adda; Marco Ambrosetti, Clinica Le Terrazze, Cunardo; Carlo, Meloni, Ospedale San Raffaele IRCCS U.O. Riabilitazione Cardiaca, Milano; Amerigo Giordano, IRCCS Fondazione Salvatore Maugeri, Lumezzane; Alberto Schizzarotto, Azienda Ospedaliera S. Antonio Abate di Gallarate, Somma Lombardo; Renzo Zanettini, Azienda Ospedaliera Istituti Clinici di Perfezionamento, Milano; Roberto Bosco, Ospedale Romano di Lombardia, Romano di Lombardia; Giuseppe Occhi, Azienda Ospedaliera della Valtellina e Valchiavenna, Sondalo; Stefano Aglieri, Istituto Clinico Humanitas, Rozzano; Giuseppe Caprioli, Humanitas, Cliniche Gavazzeni S.p.A., Bergamo; Nicola Cuocina, Azienda Ospedaliera Ospedali Riuniti di Bergamo, Bergamo; Luciano Lazzaroni, Aurelio Lorenzi, Centro di Cardiologia Riabilitativa di Cesano Boscone, Casa di Cura Ambrosiana, Cesano Boscone; Cinzia Savonelli, Cof Lanzo Hospital S.p.A. Clinica Ortopedica e Fisiatrica., Lanzo D’Intelvi; Marco Veniani, Azienda G. Salvini Garbagnate Milanese, Rho; Giovanni Corda, Azienda Ospedaliera ed Universitaria: Ospedale di Circolo ed Università dell'Insubria, Varese, Cuasso al Monte; Claudia Meinecke, Azienda Istituti Ospitalieri di Cremona, Cremona; Giuseppe Castiglioni, ASL Prov. Milano, Presidio 
Ospedaliero Cassano D’Adda, Cassano D’Adda; Ravizza Pierfranco, Azienda Ospedaliera Ospedale di Lecco, Merate; Paolo Giani, Fondazione Europea di Ricerca Biomedica Onlus, Trescore Balneario; Fabio Robustelli della CunaOspedale di Morbegno, ASL Provincia di Sondrio, Morbegno; Giuseppe Gullace, Azienda Provinciale Ospedale di Lecco, Lecco; Federico Passoni, Azienda Ospedaliera di Legnano, Cuggiono; Maria Vittoria Barelli, Centro Fisioterapico Riabilitativo Club Francesco Conti, Milano; Italo Richichi, Ospedale San Matteo U.O. di Riabilitazione, Belgioioso; Angelo Rossi, Casa di Cura Villa Esperia, Salice Terme; Alessandro Politi, Ospedale Generale di Zona, Gravedona. Marche: Romualdo Belardinelli, Azienda Ospedaliero, Universitaria Umberto I, Ancona; Casa di Cura Villa Serena, Jesi; Mauro Persico, ASUR Marche Zona Territoriale 12, San Benedetto del Tronto, Area Vasta N. 5, San Benedetto del Tronto. Piemonte e Valle d'Aosta: Pantaleo Giannuzzi, IRCCS Fondazione Salvatore Maugeri, Clinica del Lavoro e della Riabilitazione, Veruno; Gianmauro Mazzucco, Casa di Cura Villa Serena, Centro Medico di Riabilitazione Cardiologica e Pneumologica, Piossasco; Enzo Bosimini, Casa di Cura Major, Sede Distaccata IRCCS Fondazione Maugeri Veruno, Torino; Giuseppe Riva, Casa di Cura Riabilitativa Stella del Mattino, Boves; Francesco Soffiantino, Presidio Ospedaliero di Lanzo, Lanzo Torinese; Nicola Massobrio, Ospedale Evangelico Valdese di Torino, Torino; Luca Gondoni, Unità Operativa ad indirizzo Cardiologico, IRCCS Istituto Auxologico Italiano, Piancavallo di Oggebbio; Franco Aina, Azienda Ospedaliero-Universitaria Ospedale Maggiore della Carità di Novara, Novara; Biagio Ingignoli, Ospedale Ss Trinità, Fossano; Maria Vincenza Cal, Ospedale di Acqui Terme, Acqui Terme; Aillon Costante, Azienda USL Valle D’Aosta, Ospedale Regionale "Umberto Parini”, Aosta. Puglie: Domenico Scrutinio, IRCCS Fondazione Salvatore Maugeri, Cassano Murge; Massimo Villella, IRCCS Casa Sollievo della Sofferenza, San Giovanni Rotondo; Concetta La Rosa, Casa di Cura Villa Verde snc, Taranto. Sardegna: Luigi Sannia, ASL Sassari, Sassari. Sicilia: Paolo Barbanto, Presidio Ospedaliero M. Ascoli, S. Tommaselli, Azienda Ospedaliera, Catania; Antonio Castello, Ospedale Buccheri La Ferla Fatebenefratelli, Palermo; Rosario Coco, Azienda Ospedaliera Cannizzaro, Dipartimento Cardiovascolare, Catania; Renato Rametta, Azienda Ospedaliera "San Giovanni di Dio", Agrigento; Daniele Albanese, Unità di Valutazione Funzionale e Riabilitazione del Cardiopatico, Ospedale Civico A.R.N.A.S., Palermo; Antonio Circo, Casa di Cura Carmide Villa l'Ulivo, Catania; Rosaria Raciti, Centro Cuore Morgagni, Pedara; Luigi Scarnato, Casa di Cura Regina Pacis, San Cataldo; Flavia Dispensa, Fondazione Istituto San Raffaele Giglio, Cefalù; Leondardo La Spina, Centro Ionico di Cardiologia, Riposto; Alfio Stuto, Star For Life c/o Poliambulatorio di Cardiologia Dr. Armaro Biagio s.a.s., Siracusa; Calogero Vasco, Azienda Ospedaliera Umberto I, Enna; Salvatore Gibiino, Diagnostica Cardiovascolare del Dr. S. Gibiino \& C. snc., Catania; Michele Gabriele, Ospedale di Mazara Del Vallo, Mazara Del Vallo; Claudio Dispensieri, Azienda Ospedaliera Piemonte, Messina; Vittorio Carini, Casa di Cura Riabilitativa "Villa Sofia", Acireale. Toscana: Michele Provvidenza, ASL 12 Versilia, Presidio Ospedaliero di Viareggio, Lido di Camaiore;
Alessandro Scalzini, ASL 6 Livorno, Presidio Ospedaliero di Cecina, Cecina; Carlo Giustarini, Auxilium Vitae Volterra S.p.A., Volterra; Claudio Macchi, Fondazione Don Gnocchi Onlus, IRCCS, Impruneta; Francesco Fattirolli, Azienda Ospedaliero Universitaria Careggi, Firenze; Mauro Vannucci, IFCA Villa Ulivella e Glicini, Firenze; Luciana Iacopetti, ASL 3 Pistoia, Presidio Ospedaliero Pescia, Pescia; Mario Cordoni, ASL 6 Livorno, Presidio Ospedaliero di Piombino, Piombino. Trentino e Alto Adige: Ferrario Gabriele, Casa di Cura Eremo, Arco; Renato Santoni, Ospedale Classificato San Pancrazio, Arco; Walter Pitscheider, Centro di Riabilitazione del Cardiopatico, Salus Center, Bolzano; Roberto Bettini, Ospedale di Trento, Mezzolombardo; Daniela Girardini, S. Maria del Carmine, Rovereto, Centro di Riabilitazione Cardiologica Ospedale di Ala, Ala. Umbria: Sara Mandorla, ASL 1, Gualdo Tadino, Gualdo Tadino; Fabrizio Anniboletti, ASL 2 Servizio di Cardiologia Ex Ospedale Grocco Perugia, Perugia; Federico Patriarchi, UO Cardiologia Ospedale di Foligno, Nocera Umbra. Veneto: Giuseppe Favretto, Ospedale Riabilitativo di Alta Specializzazione S.p.A., Motta di Livenza; Pier Luigi Baroni, Casa di Cura Villa Garda, Garda; Fede Bordin, ASL N. 4, Presidio Ospedaliero di Thiene, Thiene; Pietro Biondi, ULSS 8, Montebelluna; Fabio Bellotto, Istituto Riabilitativo, Cortina D’Ampezzo; Albino Zanocco, Azienda Ospedaliera, Mirano; Andrea Ponchia, ULSS 16, Padova; Enzo Mantovani, Azienda ULSS 15, Camposampiero; Ennio Li Greci, Ospedale Don L. Chiarenzi, AALSS 21 Legnago (Verona), Zevio; Roberto Carlon, Azienda ALSS 15 Presidio Ospedaliero di Cittadella, Cittadella; Leopoldo Celegon, UO di Cardiologia, Riabilitazione Cardiologica, Castelfranco Veneto; Stefano Baracchi, Ospedale al Mare Lido di Venezia, Lido di Venezia; Grazia Pizzolato, AUSSL N. 10, San Donà di Piave; Lorenzo Peroni, Policlinico San Marco, Mestre; Enzo Apolloni, Ospedale di Asiago, Asiago; Gianmarco Mosele, Casa di Cura Privata Villa Margherita S.r.l., Arcugnano; Mario Guarnerio, Ospedale di Feltre, Feltre; Loris Roncon, Ospedale di Rovigo, Rovigo.

\section{References}

[1] A. J. Collins, R. N. Foley, B. M. Chavers et al., "Excerpts from the US renal data system 2009 annual data report," The American Journal of Kidney Diseases, vol. 55, no. 1, supplement 1, pp. A6A7, 2010.

[2] P. Muntner, L. L. Hamm, J. W. Kusek, J. Chen, P. K. Whelton, and $\mathrm{J}$. He, "The prevalence of nontraditional risk factors for coronary heart disease in patients with chronic kidney disease," Annals of Internal Medicine, vol. 140, no. 1, pp. 9-17, 2004.

[3] M. J. Sarnak, A. S. Levey, A. C. Schoolwerth et al., "Kidney disease as a risk factor for development of cardiovascular disease: a statement from the American heart association councils on kidney in cardiovascular disease, high blood pressure research, clinical cardiology, and epidemiology and prevention," Circulation, vol. 108, no. 17, pp. 2154-2169, 2003.

[4] N. S. Anavekar, J. J. V. McMurray, E. J. Velazquez et al., "Relation between renal dysfunction and cardiovascular outcomes after myocardial infarction," The New England Journal of Medicine, vol. 351, no. 13, pp. 1285-1295, 2004.

[5] R. S. Taylor, A. Brown, S. Ebrahim et al., "Exercise-based rehabilitation for patients with coronary heart disease: systematic 
review and meta-analysis of randomized controlled trials," The American Journal of Medicine, vol. 116, no. 10, pp. 682-692, 2004.

[6] F. Giallauria, P. Cirillo, R. Lucci et al., "Left ventricular remodelling in patients with moderate systolic dysfunction after myocardial infarction: favourable effects of exercise training and predictive role of N-terminal pro-brain natriuretic peptide," European Journal of Cardiovascular Prevention and Rehabilitation, vol. 15, no. 1, pp. 113-118, 2008.

[7] F. Giallauria, G. Galizia, R. Lucci et al., "Favourable effects of exercise-based cardiac rehabilitation after acute myocardial infarction on left atrial remodeling," International Journal of Cardiology, vol. 136, no. 3, pp. 300-306, 2009.

[8] F. Giallauria, R. Lucci, M. D’Agostino et al., "Two-year multicomprehensive secondary prevention program: favorable effects on cardiovascular functional capacity and coronary risk profile after acute myocardial infarction," Journal of Cardiovascular Medicine, vol. 10, no. 10, pp. 772-780, 2009.

[9] F. Tarro Genta, E. Eleuteri, P. L. Temporelli et al., "Flowmediated dilation normalization predicts outcome in chronic heart failure patients," Journal of Cardiac Failure, vol. 19, no. 4, pp. 260-267, 2013.

[10] F. Giallauria, P. Cirillo, M. D’Agostino et al., "Effects of exercise training on high-mobility group box-1 levels after acute myocardial infarction," Journal of Cardiac Failure, vol. 17, no. 2, pp. 108114, 2011.

[11] F. Giallauria, A. de Lorenzo, F. Pilerci et al., "Long-term effects of cardiac rehabilitation on end-exercise heart rate recovery after myocardial infarction," European Journal of Cardiovascular Prevention and Rehabilitation, vol. 13, no. 4, pp. 544-550, 2006.

[12] F. Giallauria, A. de Lorenzo, F. Pilerci et al., "Reduction of $\mathrm{N}$ terminal-pro-brain (B-type) natriuretic peptide levels with exercise-based cardiac rehabilitation in patients with left ventricular dysfunction after myocardial infarction," European Journal of Cardiovascular Prevention and Rehabilitation, vol. 13, no. 4, pp. 625-632, 2006.

[13] F. Giallauria, R. Lucci, A. de Lorenzo, M. D’Agostino, D. Del Forno, and C. Vigorito, "Favourable effects of exercise training on $\mathrm{N}$-terminal pro-brain natriuretic peptide plasma levels in elderly patients after acute myocardial infarction," Age and Ageing, vol. 35, no. 6, pp. 601-607, 2006.

[14] N. A. Smart, T. Meyer, J. A. Butterfield et al., "Individual patient meta-analysis of exercise training effects on systemic brain natriuretic peptide expression in heart failure," European Journal of Preventive Cardiology, vol. 19, no. 3, pp. 428-435, 2012.

[15] B. Rinaldi, G. Corbi, S. Boccuti et al., "Exercise training affects age-induced changes in SOD and heat shock protein expression in rat heart," Experimental Gerontology, vol. 41, no. 8, pp. 764$770,2006$.

[16] G. Byrne and F. Murphy, "Cardiac rehabilitation for patients with chronic kidney disease," Journal of Renal Care, vol. 36, supplement 1, pp. 154-162, 2010.

[17] S. Heiwe and S. H. Jacobson, "Exercise training for adults with chronic kidney disease," Cochrane Database of Systematic Reviews, no. 10, Article ID CD003236, 2011.

[18] F. Giallauria, C. Vigorito, R. Tramarin et al., "Cardiac rehabilitation in very old patients: data from the Italian survey on cardiac rehabilitation-2008 (ISYDE-2008) - official report of the Italian association for cardiovascular prevention, rehabilitation, and epidemiology," Journals of Gerontology A, vol. 65, no. 12, pp. 1353-1361, 2010.

[19] F. Giallauria, F. Fattirolli, R. Tramarin et al., "Cardiac rehabilitation in chronic heart failure: data from the Italian SurveY on
carDiac rEhabilitation (ISYDE-2008)," Journal of Cardiovascular Medicine, 2013.

[20] "National kidney foundation: clinical practice guidelines for chronic kidney disease: evaluation, classification, and stratification," The American Journal of Kidney Diseases, vol. 2, supplement1, pp. S46-S47, 2002.

[21] A. S. Levey, J. P. Bosch, J. B. Lewis, T. Greene, N. Rogers, and D. Roth, "A more accurate method to estimate glomerular filtration rate from serum creatinine: a new prediction equation," Annals of Internal Medicine, vol. 130, no. 6, pp. 461-470, 1999.

[22] M. F. Folstein, S. E. Folstein, and P. R. McHugh, “Mini-mental state': a practical method for grading the cognitive state of patients for the clinician," Journal of Psychiatric Research, vol. 12, no. 3, pp. 189-198, 1975.

[23] R. S. Wright, G. S. Reeder, C. A. Herzog et al., "Acute myocardial infarction and renal dysfunction: a high-risk combination," Annals of Internal Medicine, vol. 137, no. 7, pp. 563-570, 2002.

[24] M. G. Shlipak, P. A. Heidenreich, H. Noguchi, G. M. Chertow, W. S. Browner, and M. B. McClellan, "Association of renal insufficiency with treatment and outcomes after myocardial infarction in elderly patients," Annals of Internal Medicine, vol. 137, no. 7, pp. 555-562, 2002.

[25] R. Venkataraman, B. Sanderson, and V. Bittner, "Outcomes in patients with chronic kidney disease undergoing cardiac rehabilitation," The American Heart Journal, vol. 150, no. 6, pp. 1140-1146, 2005.

[26] W. A. Cooper, S. M. O’Brien, V. H. Thourani et al., "Impact of renal dysfunction on outcomes of coronary artery bypass surgery: results from the society of thoracic surgeons national adult cardiac database," Circulation, vol. 113, no. 8, pp. 10631070, 2006.

[27] P. J. M. Best, R. Lennon, H. H. Ting et al., "The impact of renal insufficiency on clinical outcomes in patients undergoing percutaneous coronary interventions," Journal of the American College of Cardiology, vol. 39, no. 7, pp. 1113-1119, 2002.

[28] G. Y. H. Lip, V. S. Rathore, R. Katira, S. P. Singh, and R. D. S. Watson, "Changes in renal function with percutaneous transluminal coronary angioplasty," International Journal of Cardiology, vol. 70, no. 2, pp. 127-131, 1999.

[29] R. Y. Zhang, Z. B. Zhu, Q. Zhang et al., "Impact of moderate or severe renal insufficiency on long-term outcomes in patients undergoing drug-eluting stent based coronary intervention," International Journal of Cardiology, vol. 136, no. 1, pp. 72-79, 2009.

[30] P. J. M. Best, P. B. Berger, B. R. Davis et al., "Impact of mild or moderate chronic kidney disease on the frequency of restenosis: results from the PRESTO trial," Journal of the American College of Cardiology, vol. 44, no. 9, pp. 1786-1791, 2004.

[31] G. Ashrith, V. Lee, M. A. Elayda, R. M. Reul, and J. M. Wilson, "Short- and long-term outcomes of coronary artery bypass grafting or drug-eluting stent implantation for multivessel coronary artery disease in patients with chronic kidney disease," The American Journal of Cardiology, vol. 106, no. 3, pp. 348-353, 2010.

[32] E. Selvin and T. P. Erlinger, "Prevalence of and risk factors for peripheral arterial disease in the United States: results from the national health and nutrition examination Survey, 1999-2000," Circulation, vol. 110, no. 6, pp. 738-743, 2004.

[33] I. D. Moussa, M. R. Jaff, R. Mehran et al., "Prevalence and prediction of previously unrecognized peripheral arterial disease in patients with coronary artery disease: the peripheral arterial 
disease in interventional patients study," Catheterization and Cardiovascular Interventions, vol. 73, no. 6, pp. 719-724, 2009.

[34] P. Fioretto, M. L. Caramori, and M. Mauer, "The kidney in diabetes: dynamic pathways of injury and repair. The Camillo Golgi lecture 2007," Diabetologia, vol. 51, no. 8, pp. 1347-1355, 2008.

[35] K. Yaffe, L. Ackerson, M. K. Tamura et al., "Chronic kidney disease and cognitive function in older adults: findings from the chronic renal insufficiency cohort cognitive study," Journal of the American Geriatrics Society, vol. 58, no. 2, pp. 338-345, 2010.

[36] A. S. Buchman, D. Tanne, P. A. Boyle, R. C. Shah, S. E. Leurgans, and D. A. Bennett, "Kidney function is associated with the rate of cognitive decline in the elderly," Neurology, vol. 73, no. 12, pp. 920-927, 2009.

[37] S. L. Seliger, D. S. Siscovick, C. O. Stehman-Breen et al., "Moderate renal impairment and risk of dementia among older adults: the cardiovascular health cognition study," Journal of the American Society of Nephrology, vol. 15, no. 7, pp. 1904-1911, 2004.

[38] T. Etgen, D. Sander, M. Chonchol et al., "Chronic kidney disease is associated with incident cognitive impairment in the elderly: the INVADE study," Nephrology Dialysis Transplantation, vol. 24, no. 10, pp. 3144-3150, 2009.

[39] T. L. Nickolas, M. Khatri, B. Boden-Albala et al., "The association between kidney disease and cardiovascular risk in a multiethnic cohort: findings from the Northern manhattan study (NOMAS)," Stroke, vol. 39, no. 10, pp. 2876-2879, 2008.

[40] R. L. C. Vogels, P. Scheltens, J. M. Schroeder-Tanka, and H. C. Weinstein, "Cognitive impairment in heart failure: a systematic review of the literature," European Journal of Heart Failure, vol. 9, no. 5, pp. 440-449, 2007.

[41] L. Trojano, R. A. Incalzi, D. Acanfora, C. Picone, P. Mecocci, and F. Rengo, "Cognitive impairment: a key feature of congestive heart failure in the elderly," Journal of Neurology, vol. 250, no. 12, pp. 1456-1463, 2003.

[42] B. C. Astor, P. Muntner, A. Levin, J. A. Eustace, and J. Coresh, "Association of kidney function with anemia: the third national health and nutrition examination survey (1988-1994)," Archives of Internal Medicine, vol. 162, no. 12, pp. 1401-1408, 2002.

[43] A. S. Go, J. Yang, L. M. Ackerson et al., "Hemoglobin level, chronic kidney disease, and the risks of death and hospitalization in adults with chronic heart failure-the anemia in chronic heart failure: outcomes and resource utilization (ANCHOR) study," Circulation, vol. 113, no. 23, pp. 2713-2723, 2006.

[44] P. R. Kalra, A. P. Bolger, D. P. Francis et al., "Effect of anemia on exercise tolerance in chronic heart failure in men," The American Journal of Cardiology, vol. 91, no. 7, pp. 888-891, 2003.

[45] F. Locatelli, P. Aljama, B. Canaud et al., "Target haemoglobin to aim for with erythropoiesis-stimulating agents: a position statement by ERBP following publication of the trial to reduce cardiovascular events with aranesp therapy (TREAT) study," Nephrology Dialysis Transplantation, vol. 25, no. 9, pp. 28462850, 2010.

[46] P. H. Stone, Z. G. Turi, J. E. Muller et al., "Prognostic significance of the treadmill exercise test performance 6 months after myocardial infarction," Journal of the American College of Cardiology, vol. 8, no. 5, pp. 1007-1017, 1986.

[47] M. F. Piepoli, U. Corrà, W. Benzer et al., "Secondary prevention through cardiac rehabilitation: from knowledge to implementation. A position paper from the cardiac rehabilitation section of the european association of cardiovascular prevention and rehabilitation," European Journal of Cardiovascular Prevention and Rehabilitation, vol. 17, no. 1, pp. 1-17, 2010.

[48] R. G. Hawkins and M. C. Houston, "Is population-wide diuretic use directly associated with the incidence of end-stage renal disease in the United States? A hypothesis," The American Journal of Hypertension, vol. 18, no. 6, pp. 744-749, 2005.

[49] C. Bruch, M. Rothenburger, M. Gotzmann et al., "Chronic kidney disease in patients with chronic heart failure-impact on intracardiac conduction, diastolic function and prognosis," International Journal of Cardiology, vol. 118, no. 3, pp. 375-380, 2007.

[50] N. A. Smart, G. Dieberg, and F. Giallauria, "Intermittent versus continuous exercise training in chronic heart failure: a metaanalysis," International Journal of Cardiology, vol. 166, no. 2, pp. 352-358, 2013.

[51] N. A. Smart, G. Dieberg, and F. Giallauria, "Functional electrical stimulation for chronic heart failure: a meta-analysis," International Journal of Cardiology, vol. 167, no. 1, pp. 80-85, 2013.

[52] N. A. Smart, F. Giallauria, and G. Dieberg, "Efficacy of inspiratory muscle training in chronic heart failure patients: a systematic review and meta-analysis," International Journal of Cardiology, 2012. 


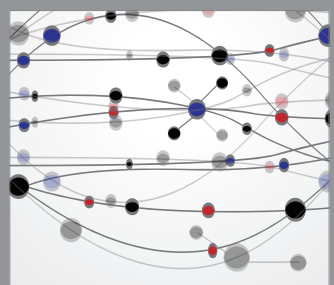

The Scientific World Journal
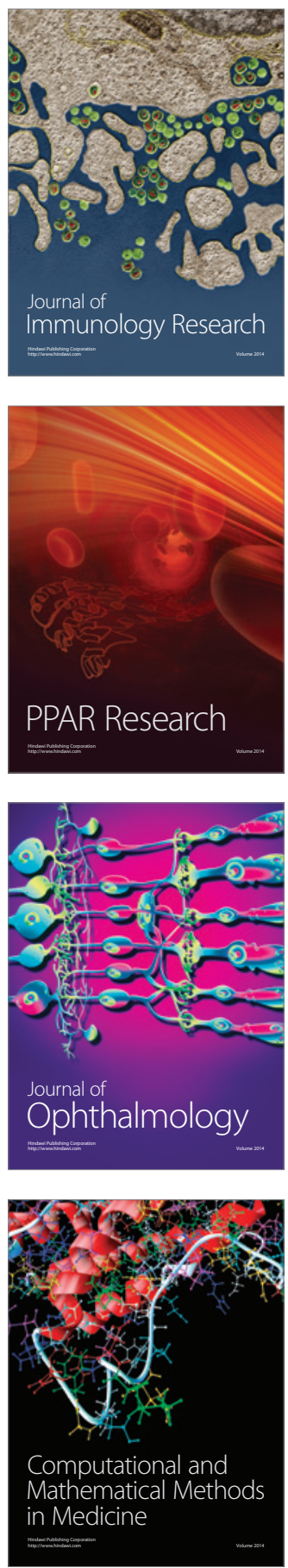

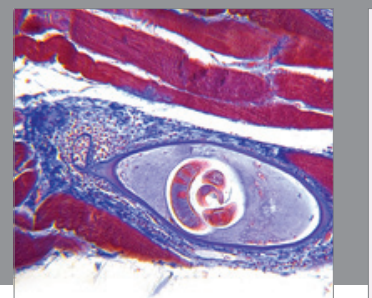

Gastroenterology

Research and Practice
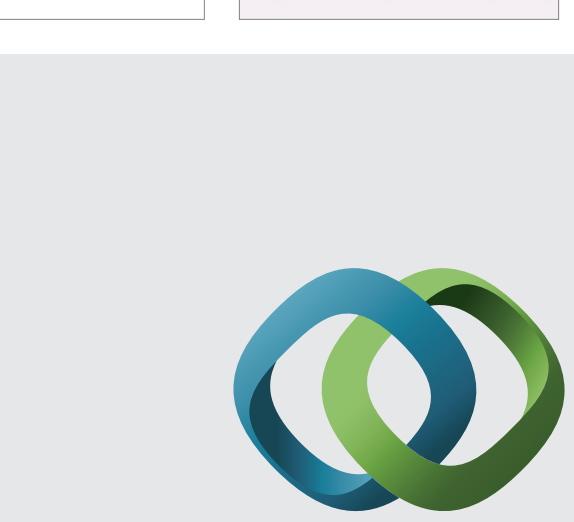

\section{Hindawi}

Submit your manuscripts at

http://www.hindawi.com
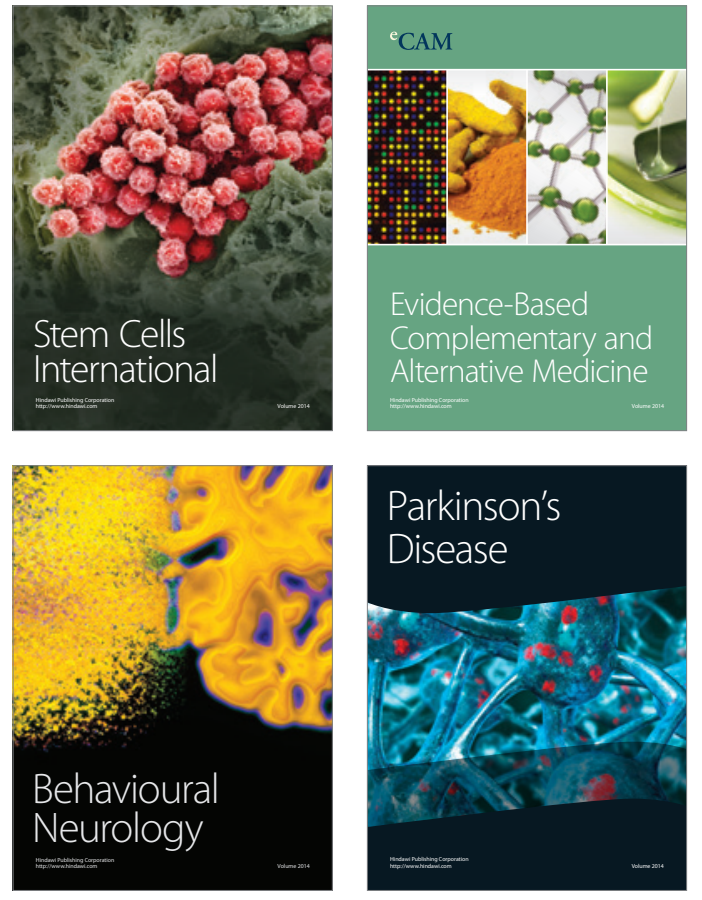
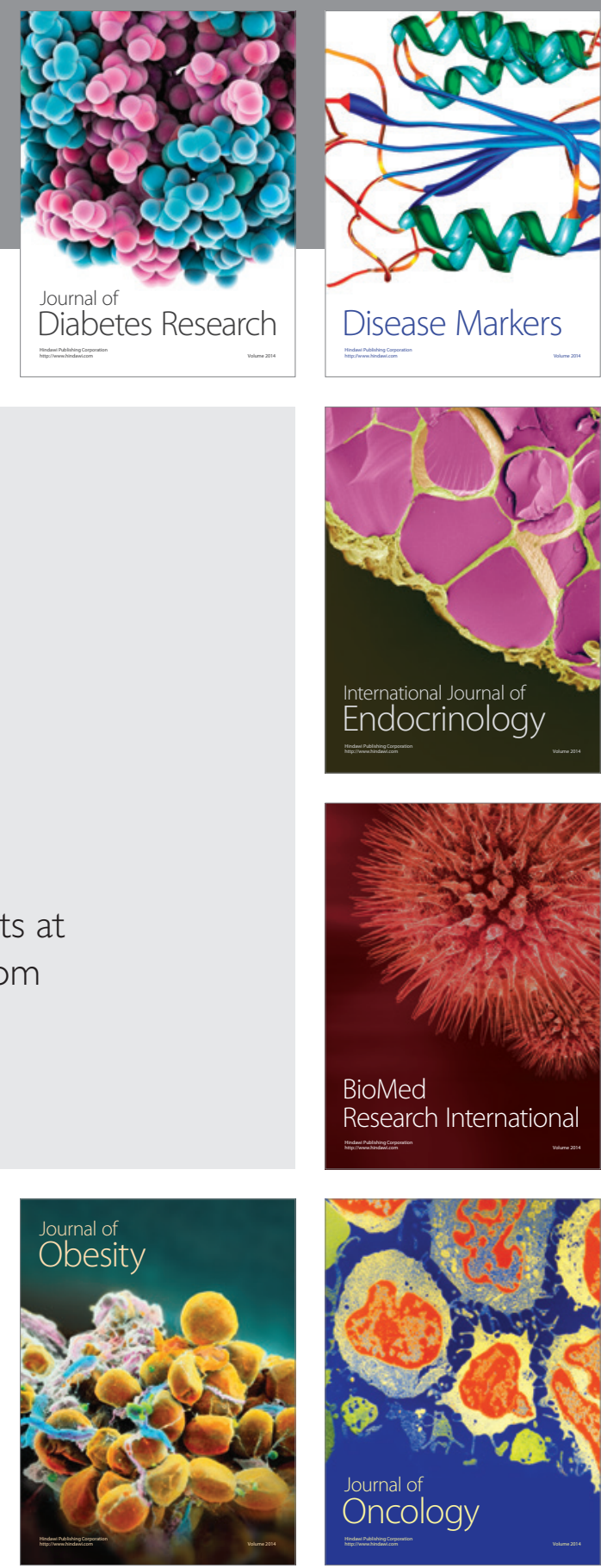

Disease Markers
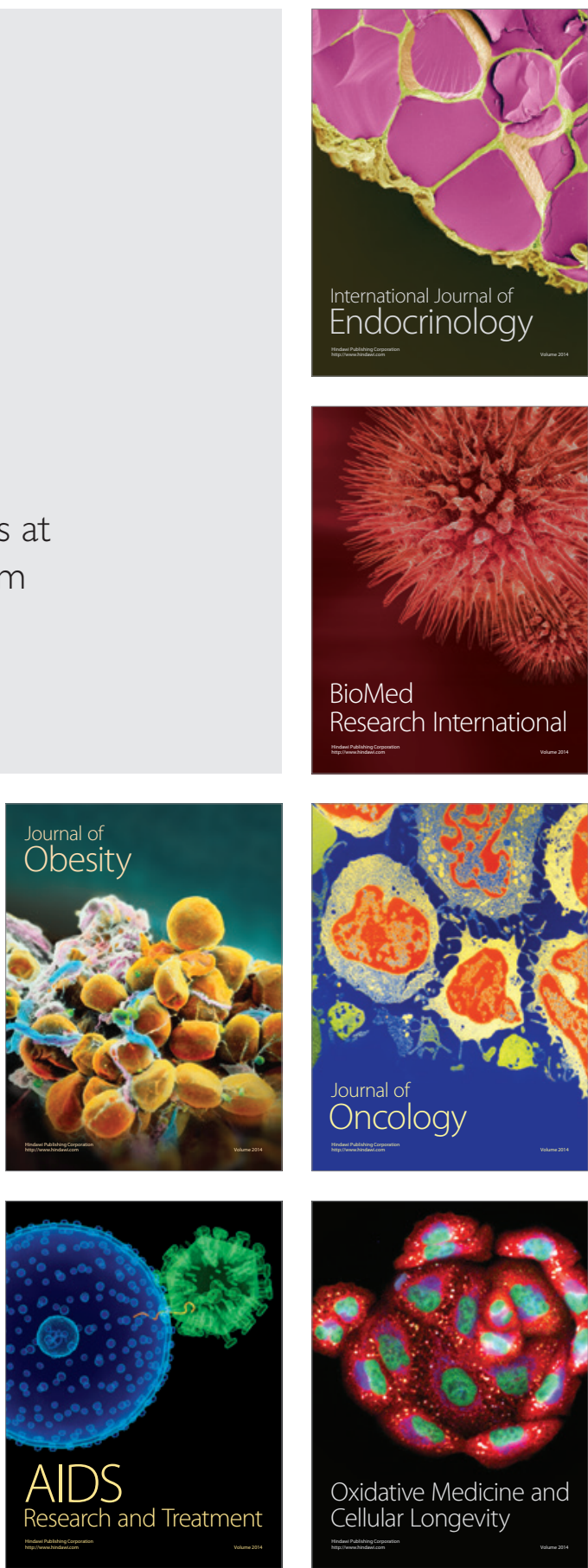